\title{
Portal Vein Embolization is Associated with Reduced Liver Failure and Mortality in High-Risk Resections for Perihilar Cholangiocarcinoma
}

\author{
Pim B. Olthof, MD, $\mathbf{P h D}^{1,2}$, Luca Aldrighetti, $\mathrm{MD}, \mathbf{P h D}^{3}$, Ruslan Alikhanov, $\mathbf{M D}, \mathbf{P h D}^{3,4}$, \\ Matteo Cescon, $\mathrm{MD}, \mathrm{PhD}^{5}$, Bas Groot Koerkamp, $\mathrm{MD}, \mathrm{PhD}^{2}$, William R. Jarnagin, $\mathrm{MD}^{\mathbf{6}}$, \\ Silvio Nadalin, $\mathrm{MD}^{7}$, Johann Pratschke, MD, $\mathrm{PhD}^{8}$, Moritz Schmelze, $\mathrm{MD}^{8}$, Ernesto Sparrelid, MD, $\mathrm{PhD}^{9}$, \\ Hauke Lang, $\mathrm{MD}^{10}$, Alfredo Guglielmi, $\mathrm{MD}^{11}$, Thomas $\mathrm{M}$. van Gulik, $\mathrm{MD}, \mathrm{PhD}^{1}$ on behalf of the Perihilar \\ Cholangiocarcinoma Collaboration Group
}

${ }^{1}$ Department of Surgery, Amsterdam UMC (location AMC), University of Amsterdam, Amsterdam, The Netherlands;
${ }^{2}$ Department of Surgery, Erasmus Medical Center, Rotterdam, The Netherlands; ${ }^{3}$ Hepato-biliary Surgery Division,
Ospedale San Raffaele-IRCCS, Milan, Italy; ${ }^{4}$ Department of Hepato-Pancreato-Biliary Surgery, Moscow Clinical
Scientific Center, Moscow, Russia; ${ }^{5}$ Department of Medical and Surgical Sciences, S. Orsola-Malpighi Hospital, Alma
Mater Studiorum - University of Bologna, Bologna, Italy; ${ }^{6}$ Division of Hepatopancreatobiliary Surgery, Memorial Sloan-
Kettering Cancer Center, New York, NY; ${ }^{7}$ Department of General and Transplant Surgery, University Hospital Tübingen,
Tübingen, Germany; ${ }^{8}$ Department of General, Visceral and Transplantation Surgery, Charité University Hospital, Berlin,
Germany; ${ }^{9}$ Department of Surgery, Centre for Digestive Diseases, Karolinska University Hospital, Stockholm, Sweden;
${ }^{10}$ Department of General, Visceral and Transplantation Surgery, University Hospital of Mainz, Mainz, Germany;
${ }^{11}$ Department of Surgery, Unit of Hepato-Pancreato-Biliary Surgery, University of Verona Medical School, Verona, Italy

\section{ABSTRACT}

Background. Preoperative portal vein embolization (PVE) is frequently used to improve future liver remnant volume (FLRV) and to reduce the risk of liver failure after major liver resection.

Objective. This paper aimed to assess postoperative outcomes after PVE and resection for suspected perihilar cholangiocarcinoma (PHC) in an international, multicentric cohort.

Methods. Patients undergoing resection for suspected PHC across 20 centers worldwide, from the year 2000, were included. Liver failure, biliary leakage, and hemorrhage were classified according to the respective

This work was presented in the Best Paper session of the 13th Congress of the European-African Hepato-Pancreato-Biliary Association, Amsterdam, The Netherlands, 2-5 June 2019.

(C) The Author(s) 2020

First Received: 28 September 2019;

Published Online: 26 February 2020

P. B. Olthof, MD, PhD

e-mail: p.b.olthof@amc.nl
International Study Group of Liver Surgery criteria. Using propensity scoring, two equal cohorts were generated using matching parameters, i.e. age, sex, American Society of Anesthesiologists classification, jaundice, type of biliary drainage, baseline FLRV, resection type, and portal vein resection.

Results. A total of 1667 patients were treated for suspected PHC during the study period. In 298 patients who underwent preoperative PVE, the overall incidence of liver failure and 90-day mortality was $27 \%$ and $18 \%$, respectively, as opposed to $14 \%$ and $12 \%$, respectively, in patients without PVE $(p<0.001$ and $p=0.005)$. After propensity score matching, 98 patients were enrolled in each cohort, resulting in similar baseline and operative characteristics. Liver failure was lower in the PVE group ( $8 \%$ vs. $36 \%, p<0.001$ ), as was biliary leakage ( $10 \%$ vs. $35 \%, p<0.01)$, intra-abdominal abscesses $(19 \%$ vs. $34 \%$, $p=0.01$ ), and 90 -day mortality ( $7 \%$ vs. $18 \%, p=0.03$ ).

Conclusion. PVE before major liver resection for PHC is associated with a lower incidence of liver failure, biliary leakage, abscess formation, and mortality. These results demonstrate the importance of PVE as an integral component in the surgical treatment of PHC. 
Portal vein embolization (PVE) is considered the goldstandard procedure to enhance the future liver remnant (FLR) before major liver resection and to reduce the risk of postoperative liver failure and mortality. ${ }^{1,2}$ Since its introduction more than three decades ago, PVE has shown to induce an increase in FLR volume (FLRV) in both healthy and compromised liver parenchyma, while associated with minimal adverse events. ${ }^{3-5}$ A decrease in postoperative liver failure using PVE has frequently been reported; however, in the only prospective comparative clinical trial, undertaken by Farges et al. in 2003, PVE decreased postoperative complications only in patients with compromised liver parenchyma at increased risk of liver failure. ${ }^{6}$

Patients with perihilar cholangiocarcinoma (PHC) are especially at risk for liver failure due to biliary obstruction and cholestasis frequently encountered in these patients and which profoundly compromise the liver's regenerative capacity. ${ }^{7,8}$ The vast majority of these patients require major liver resection to obtain tumor-free margins, leaving a small liver remnant that is also not able to efficiently regenerate. Therefore, biliary drainage is an essential component in the preoperative work-up of these patients in order to reduce the risk of adverse events. Liver failure and mortality rates are reported to be between 17 and $24 \%$ and 10 and 14\%, respectively, and have remained high in Western series. ${ }^{9-13}$

Several studies addressed the use of PVE in patients with PHC and showed increases in liver volume; however, comparative studies demonstrating a beneficial effect of PVE on adverse events after resection are currently lacking for PHC. ${ }^{14-16}$ Therefore, this study aimed to evaluate the effect of PVE on the risk of morbidity and mortality after resection for PHC in a large multicentric Western cohort.

\section{METHODS}

All 20 participating centers included a median of 80 (25-115) consecutive resections for presumed PHC without a required fixed timespan but not preceding the year 2000. Each center included their retrospective series using a standardized and anonymized data file. PHC was defined as a suspicious biliary tumor originating at the hepatic duct confluence between the segmental bile ducts and cystic duct. For the current study, all patients who had only undergone excision of the extra hepatic bile ducts, explorative laparotomy, or liver transplantation were excluded. The need for ethical approval and individual informed consent was waived by the Institutional Medical Ethics Committee of the Amsterdam University Medical Center.

\section{Patient Work-Up and Management}

The multicenter set-up of the current study inevitably led to differences in the work-up and management of the included patients. Therefore, the selection of patients for PVE and biliary drainage differed between centers. In general, most patients planned for large liver resections underwent preoperative, endoscopic, or transhepatic biliary drainage of at least the FLR.

\section{Outcome Parameters}

Preoperative cholangitis was defined as fever and leukocytosis requiring (additional) biliary drainage in accordance with the definitions applied in the DROP and DRAINAGE trials dealing with preoperative biliary drainage. ${ }^{17,18}$ Major liver resection was defined as resection of at least three Couinaud liver segments. The liver remnant volume share (FLRV) was calculated by dividing the FLRV (in milliliters) by the total liver volume (in milliliters) and multiplying by $100 \%$. R0 resection margins were defined as tumor-free margins in all reported margins in the respective pathology reports. All complications within 30 days after surgery were scored and classified according to the Dindo classification system, with grade III or higher considered as major morbidity. Liver failure, biliary leakage, and hemorrhage were scored and classified according to the respective International Study Group of Liver Surgery (ISGLS) criteria, and only grades B and C were considered as clinically relevant. ${ }^{19-21}$ Perioperative mortality was defined as death within 90 days after surgery, while overall survival was defined as the time between surgery and death, or date of last follow-up.

\section{Statistical Analyses}

Categorical variables were reported as numbers with percentages, and tested using Chi square or Fisher's exact tests when the expected cell count in a category was $<5$. Continuous variables were displayed as median with interquartile range (IQR), and tested using Mann-Whitney $U$ tests. Propensity score matching was performed using the psmatching 3 plugin for SPSS using nearest-neighbor matching (1:1) with a caliper of 0.2. Matching parameters included age, sex, American Society of Anesthesiologists (ASA) classification, jaundice at presentation, biliary drainage, baseline FLRV share (before PVE), type of resection, and concomitant vascular resections. Statistical analyses were performed using SPSS (IBM Corporation, Armonk, NY, USA). 


\section{RESULTS}

A total of 1667 patients from 20 participating centers were enrolled. Of these, the following cases were excluded: 37 un-resectable cases, 140 patients with extrahepatic bile duct resection only, and 6 patients undergoing liver transplantation. The remaining 1484 patients all underwent combined liver and biliary resection for presumed PHC (Table 1).

Overall, most patients (90\%) suffered from jaundice and consequently the majority underwent biliary drainage before surgery $(83 \%)$, at the expense of preoperative cholangitis in $22 \%$ of patients. The majority of patients underwent either right (49\%) or left (47\%) liver resection, and portal vein reconstruction was performed in $32 \%$ of cases. The overall liver failure rate was $17 \%$ and 90 -day mortality was $13 \% .94 \%$ of patients had a pathology-confirmed diagnosis of PHC in the resection specimen, of whom $66 \%$ had tumor-free resection margins.

In this study, 298 (20\%) patients underwent PVE before liver resection (Table 1). There was large variety in the use of PVE across institutions (Fig. 1a), showing a trend towards more frequent use in more recent years (Fig. 1b). The right and left liver segments were embolized in 277
TABLE 1 Baseline and operative characteristics

\begin{tabular}{|c|c|c|c|}
\hline & PVE $(n=298)$ & No PVE $(n=1186)$ & $p$ Value \\
\hline Age, years [median (IQR); $n=1484$ ] & $64(56-71)$ & $65(57-72)$ & 0.302 \\
\hline Male sex $(n=1484)$ & $150(50)$ & $700(59)$ & 0.007 \\
\hline ASA classification $(n=1386)$ & & & 0.574 \\
\hline I & $24(8)$ & $127(12)$ & \\
\hline II & $155(54)$ & $554(50)$ & \\
\hline III & $104(36)$ & $404(37)$ & \\
\hline IV & $4(1)$ & $14(1)$ & \\
\hline Jaundice at presentation $(n=1370)$ & $233(86)$ & $861(78)$ & 0.001 \\
\hline Baseline bilirubin level [median (IQR); $n=1108$ ] & $86(16-207)$ & $58(15-171)$ & $<0.001$ \\
\hline Biliary drainage $(n=1370)$ & & & $<0.001$ \\
\hline None & $22(8)$ & $213(18)$ & \\
\hline PTBD & $74(25)$ & $300(25)$ & \\
\hline EBD & $138(47)$ & $502(43)$ & \\
\hline Both & $61(21)$ & $165(14)$ & \\
\hline Preoperative cholangitis $(n=1400)$ & $63(21)$ & $238(22)$ & 1.000 \\
\hline Bismuth classification $(n=1452)$ & & & $<0.001$ \\
\hline Left/right duct & $4(1)$ & $32(3)$ & \\
\hline I & $16(6)$ & $41(4)$ & \\
\hline II & $23(8)$ & $117(10)$ & \\
\hline IIIA & $139(48)$ & $329(28)$ & \\
\hline IIIB & $12(4)$ & $367(32)$ & \\
\hline IV & $95(33)$ & $277(24)$ & \\
\hline Resection type $(n=1484)$ & & & $<0.001$ \\
\hline Left hemihepatectomy & $18(6)$ & $442(37)$ & \\
\hline Extended left hemihepatectomy & $3(1)$ & $233(20)$ & \\
\hline Right hemihepatectomy & $56(19)$ & $191(16)$ & \\
\hline Extended right hemihepatectomy & $221(74)$ & $265(22)$ & \\
\hline Other & - & $55(5)$ & \\
\hline Portal vein reconstruction $(n=1481)$ & $148(50)$ & $327(28)$ & $<0.001$ \\
\hline \multicolumn{4}{|l|}{ Future liver remnant volume share [median (IQR)] } \\
\hline Baseline $(n=510)$ & $23(19-29)$ & - & \\
\hline After PVE $(n=131)$ & $33(27-39)$ & $42(31-66)$ & $<0.001$ \\
\hline Preoperative bilirubin level [median (IQR); $n=1068$ ] & $15(8-35)$ & $21(10-44)$ & $<0.001$ \\
\hline
\end{tabular}

Data are expressed as $n(\%)$ unless otherwise specified

$P V E$ Portal vein embolization, $I Q R$ interquartile range, $A S A$ American Society of Anesthesiologists, $P T B D$ percutaneous transhepatic biliary drainage, $E B D$ endoscopic biliary drainage 

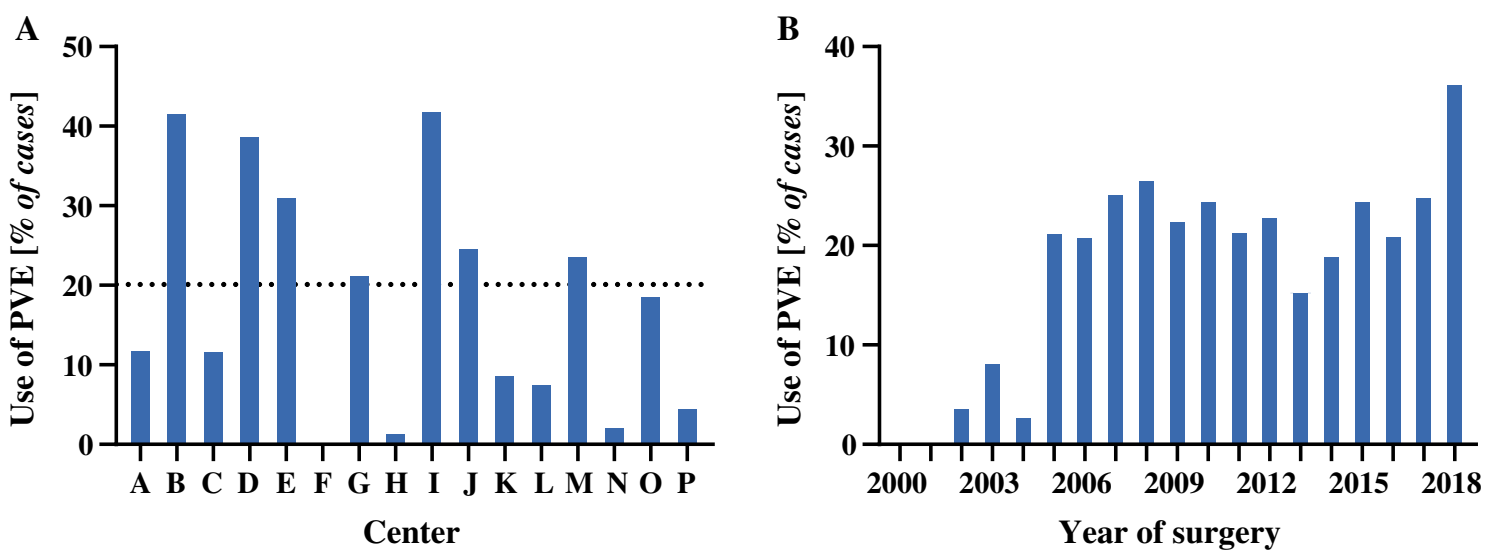

FIG. 1 a Differential use of PVE across institutions with at least 15 included cases. The dotted line represents the use of PVE in the entire cohort. b Use of PVE per year in the cohort. PVE portal vein embolization

(93\%) and $21(7 \%)$ patients, respectively. Segment 4 embolization was performed in $16 \%$ of all PVE procedures. In $73 \%$, the embolic material consisted of particles in combination with coils or a plug; in $23 \%$, glue-like materials were used; and the remaining $4 \%$ of PVE procedures were performed using a combination of the two. The rates of PVE were higher among right liver resections (38\%, 277/733) compared with left liver resections (3\%, 21/696), and were highest for extended right liver resections (45\%, 221/486). The higher rates of biliary drainage, predominantly larger resections in right (extended) liver resections and consequently smaller remnant livers, as well as more frequent portal vein resections, indicate the higher risk of resections undertaken after PVE compared with resections without PVE. These risks are confirmed by the outcomes reported in Table 2 showing more frequent major complications, liver failure, and higher mortality in PVE patients.
Standard left-liver resections allow for a larger liver remnant with lower operative risks, rendering PVE not often necessary in this group of patients. Assessment of the outcomes after PVE should therefore be related to the type/ extent of resection. When comparing only right (extended) liver resections, the risks were more equal, with liver failure and mortality rates of $25 \%$ and $19 \%$, respectively, in the 277 patients with PVE, compared with $23 \%$ and $16 \%$ in the 456 patients without $\operatorname{PVE}(p=0.473$ and $p=0.419)$; however, direct comparison of these cohorts is hampered by the wide selection of patients.

\section{Propensity Score Matched Cohort}

In order to be able to analyze the true effects of PVE on postoperative outcomes, a propensity matched comparison was performed using only cases with complete data on all relevant parameters. After exclusion of cases with missing volume parameters, a total of 510 patients (151 with PVE
TABLE 2 Postoperative outcomes

\begin{tabular}{lccr}
\hline & PVE $(n=298)$ & No PVE $(n=1186)$ & $p$-Value \\
\hline Pathology diagnosis $(n=1460)$ & & & 0.830 \\
Perihilar cholangiocarcinoma & $279(95)$ & $1088(93)$ & \\
Benign & $6(2)$ & $29(3)$ & \\
Other & $8(3)$ & $48(4)$ & 0.341 \\
Tumor-free margin $(n=1417)$ & $185(64)$ & $745(66)$ & $<0.001$ \\
Morbidity Dindo grade III or higher $(n=1474)$ & $177(59)$ & $520(44)$ & $<0.001$ \\
Liver failure ISGLS grade B/C $(n=1472)$ & $81(27)$ & $166(14)$ & 0.690 \\
Biliary leakage ISGLS grade B/C $(n=1475)$ & $59(20)$ & $248(21)$ & 0.078 \\
Hemorrhage ISGLS grade B/C $(n=1214)$ & $18(10)$ & $61(6)$ & 0.127 \\
Intra-abdominal abscess $(n=1475)$ & $50(17)$ & $257(22)$ & 0.005 \\
90-day mortality $(n=1484)$ & $53(18)$ & $136(12)$ & \\
\hline
\end{tabular}

Data are expressed as $n(\%)$

PVE Portal vein embolization, ISGLS International Study Group of Liver Surgery 
and 359 without) were available for matching. Based on all parameters relevant for postoperative outcomes, two matched cohorts of 98 patients were generated (Table 3 ). The matched cohorts were equal in all preoperative and operative variables, including the baseline FLRV share, which increased a median of 7 percentage points after PVE. The increase in true remnant liver volume after PVE was $42 \%$
(18-59) in a median of 22 (19-29) days. The use of PVE was associated with reductions in liver failure (from $36 \%$ to $8 \% ; 4.4$-fold reduction) and biliary leakage (from 35 to $10 \%$; 3.5-fold reduction), and a decrease in 90-day mortality (from 18 to $7 \%$; 2.6 -fold reduction).
TABLE 3 Propensity score matched comparison

\begin{tabular}{|c|c|c|c|}
\hline & $\operatorname{PVE}(n=98)$ & No PVE $(n=98)$ & $p$-Value \\
\hline Age, years [median (IQR)] & $65(57-71)$ & $63(56-71)$ & 0.606 \\
\hline Male sex & $55(66)$ & $61(62)$ & 0.468 \\
\hline ASA classification & & & 0.648 \\
\hline I & $10(10)$ & $14(14)$ & \\
\hline II & $46(47)$ & $46(47)$ & \\
\hline III & $42(43)$ & $38(39)$ & \\
\hline Jaundice at presentation & $74(76)$ & $73(74)$ & 1.000 \\
\hline Baseline bilirubin level [median (IQR)] & $60(15-213)$ & $48(13-135)$ & 0.384 \\
\hline Biliary drainage & & & 0.601 \\
\hline None & $11(11)$ & $12(12)$ & \\
\hline PTBD & $34(35)$ & $26(27)$ & \\
\hline EBD & $29(30)$ & $36(37)$ & \\
\hline Both & $24(25)$ & $24(25)$ & \\
\hline Preoperative cholangitis & $28(29)$ & $24(25)$ & 0.628 \\
\hline Bismuth classification & & & 0.086 \\
\hline Left/right duct & $2(3)$ & $3(3)$ & \\
\hline I & $7(7)$ & $3(3)$ & \\
\hline II & $7(7)$ & $17(17)$ & \\
\hline IIIA & $49(51)$ & $46(47)$ & \\
\hline IIIB & $3(3)$ & $9(9)$ & \\
\hline IV & $27(28)$ & $20(20)$ & \\
\hline Future liver remnant volume share [median (IQR)] & & & 0.130 \\
\hline Baseline & $27(21-32)$ & - & \\
\hline After PVE & $35(28-42)$ & $29(23-33)$ & $<0.01$ \\
\hline Preoperative bilirubin level [median (IQR)] & $12(5-27)$ & $15(9-38)$ & 0.057 \\
\hline Resection type & & & 0.481 \\
\hline Left hemihepatectomy & $2(2)$ & $5(5)$ & \\
\hline Extended left hemihepatectomy & $1(1)$ & $2(2)$ & \\
\hline Right hemihepatectomy & $35(36)$ & $28(29)$ & \\
\hline Extended right hemihepatectomy & $60(61)$ & $63(64)$ & \\
\hline Portal vein resection & $18(18)$ & $21(21)$ & 0.721 \\
\hline Estimated blood loss [median (IQR)] & $775(500-1300)$ & $900(600-1996)$ & 0.054 \\
\hline Morbidity Dindo grade III or higher & $50(51)$ & $53(54)$ & 0.775 \\
\hline Liver failure ISGLS grade B/C & $8(8)$ & $35(36)$ & $<0.001$ \\
\hline Biliary leakage ISGLS grade $\mathrm{B} / \mathrm{C}$ & $10(10)$ & $34(35)$ & $<0.001$ \\
\hline Hemorrhage ISGLS grade B/C & $6(6)$ & $7(7)$ & 1.000 \\
\hline Intra-abdominal abscess & 19 (19) & $33(34)$ & 0.034 \\
\hline 90-day mortality & $7(7)$ & $18(18)$ & 0.031 \\
\hline
\end{tabular}

Data are expressed as $n(\%)$ unless otherwise stated

$P V E$ Portal vein embolization, IQR interquartile range, ASA American Society of Anesthesiologists, PTBD percutaneous transhepatic biliary drainage, $E B D$ endoscopic biliary drainage 


\section{DISCUSSION}

This study describes a large Western cohort of combined hepatic and biliary resections for PHC and included 1484 patients among 20 centers. Overall, 20\% of patients underwent PVE before liver resection, but the use of PVE varied considerably across centers. The overall postoperative outcomes demonstrated that patients who underwent PVE were high surgical risks, showing higher rates of adverse events following resection, but any comparison is limited by selection. In a propensity score matched analysis, the effect of PVE on postoperative outcomes was assessed in two equal cohorts of 98 patients. Although preoperative parameters were similar, the incidences of liver failure, biliary leakage, intra-abdominal abscesses, and postoperative mortality were lower in the PVE group compared with patients without PVE. These outcomes in the high-risk patients who underwent PVE were all well below the rates in the overall cohort, while all rates of the matched patients without PVE stand well above those in the entire cohort.

The only prospective trial dealing with PVE showed a reduction in postoperative morbidity in patients with compromised liver parenchyma who underwent preoperative PVE; however, this trial included only patients undergoing standard right hemihepatectomy and no patients with PHC. ${ }^{6}$ Specifically in PHC, a study from a high-volume center in Japan reported a postoperative mortality rate of $4.5 \%$ in 132 patients who underwent PVE for an anticipated liver remnant of $<40 \%$, while mortality was $3.7 \%$ in 136 patients who underwent resection of $<50 \%$ of liver volume without PVE. ${ }^{22}$ These results illustrate that PVE reduces operative risks since the former can be considered high-risk resections compared with patients with a remnant liver of $50 \%$ or higher; however, a direct comparison was not reported. The current analyses using a matched cohort of patients with and without PVE clearly demonstrates a reduction in postoperative rates of liver failure and mortality.

Although these results confirm the expected risk-reducing effects of PVE before major liver resection, PVE is only sparsely used in Western series. This is in contrast with the frequent use of PVE in Eastern series; ${ }^{23}$ Eastern centers often report the use of PVE in the majority of patients. ${ }^{23-25}$ The largest single-center series reported use of PVE in $60 \%$ of patients and while the rates of liver failure were comparable (32\%), mortality was substantially lower at only $2 \% .{ }^{25}$ This remarkable difference in mortality has been noted across literature ${ }^{23,26}$ and could well be due to the higher rates of PVE used in Eastern centers. ${ }^{12,23}$

The use of PVE extends the time until resection by at least 3-6 weeks in order to allow sufficient growth of the anticipated remnant liver. ${ }^{5}$ In the interval to surgery, these patients are at risk of developing cholangitis, which is associated with high rates of liver failure and mortality after hepatectomy. ${ }^{11,12,27,28}$ Cholangitis was not included as a matching parameter in the current analyses. In the matched comparison, the incidence of preoperative cholangitis was similar, suggesting that the increased time to surgery associated with PVE had little impact on outcomes. Furthermore, despite similar episodes of cholangitis, liver failure and mortality were reduced in patients who underwent PVE, which suggests that the protective effect of PVE overruled the negative effects of PVE. ${ }^{11,12}$ Considering the negative impact of cholangitis on outcomes, PVE should perhaps be liberally considered in this subgroup of patients, although direct evidence is lacking and will likely be difficult to obtain.

The selection of patients with PHC for PVE is a challenge since the obstructive cholestasis and accompanying biliary drainage and cholangitis are associated with loss of remnant liver function, in addition to its size alone. ${ }^{12}$ The most frequently used remnant volume cut-off value is $40 \%,{ }^{14}$ but literature is equivocal and liver volume alone has insufficient predictive value for accurate patient selection for PVE. ${ }^{12,14,29}$ Several modalities for functional assessment of the remnant liver have been proposed to aid in the decision to perform PVE. Indocyanine green clearance tests have shown added value, over volume alone, to predict adverse outcomes, however the negative predictive value that is essential to select patients for PVE is low. ${ }^{25,30-32}$ In other words, a value for sufficient liver function to safely proceed without the need for PVE would benefit patient selection. Hepatobiliary scintigraphy (HBS) with technetium-labeled mebrofenin could help to achieve this goal. The usual cut-off value used in previous publications has been $2.7 \% \mathrm{~min}^{-1} \mathrm{~m}^{-2}$ based on body surface area; however, a recent report demonstrated a body surface area uncorrected remnant liver function of $8.5 \% / \mathrm{min}$ to be safe. ${ }^{29}$ This relatively high cut-off value potentially leads to high rates of PVE but since complications and adverse outcomes of PVE are rare, this is likely a valuable approach to improve outcomes. ${ }^{29,33}$ Adherence to such recommendations likely reduces the relatively high liver failure rates still observed in PHC patients when adhering to the $2.7 \% \mathrm{~min}^{-1} \mathrm{~m}^{-2}$ cut-off. $^{29}$

Although 298 patients underwent PVE in the current cohort, only 98 patients were matched, for several reasons. First, only patients with complete data, i.e. without any missing data, were included to ensure high-quality analysis. Due to the relatively low number of patients with data on liver volumes, which is an essential parameter to assess operative risks, the number of patients eligible for matching was limited. Second, patients who underwent PVE had small remnant livers, whereas a low number of patients with small remnant livers were exposed to resection 
without PVE due to the obvious risk of liver failure. This difference limits the ability to generate a large and wellmatched cohort. Despite these limitations, the current strategy is likely the most accurate possible and the closest to a randomized trial, which will obviously not be possible to set-up because of ethical reasons. The retrospective study design is another limitation and leaves the study subject to selection bias. The time required between PVE and resection can be considered a test of time in the selection of patients with more favorable tumor biology. In addition, patients lacking an adequate hypertrophy response after PVE have likely not been subjected to surgery. Additionally, there may have been differences in patient selection for PVE as well as criteria to proceed to surgery, which could have affected the results; however, randomized studies in PHC are difficult to perform due to the rarity of the disease. The current cohort was a large Western multicenter cohort, which improves its reliability. Eastern centers were deliberately not included in the series for these analyses due to the differences in management and outcomes. Future studies should also confirm these findings in Eastern patients. ${ }^{23,26}$ Finally, some patients will have undergone PVE but no resection, however these patients were not included in this study, which could be a confounding factor. However, since approximately $37-46 \%{ }^{34-36}$ of patients are found to be unresectable at laparotomy regardless of PVE, including these patients would have resulted in results that would be difficult to interpret.

\section{CONCLUSION}

The propensity score matched comparison in this multicenter cohort of 1484 patients showed that PVE was associated with a 4.4-fold reduction in liver failure and a 2.6-fold reduction in 90-day mortality in patients undergoing major liver resection for PHC. These outcomes in these high-risk patients after PVE are better than the outcomes in the overall cohort and show that PVE can be essential for decreasing surgical risk in these patients. Although the exact indications for PVE in patients with PHC are not clearly defined, and the use of PVE varies widely across centers, a liberal approach to the application of PVE in patients with future livers remnant $<40 \%$ is likely to improve postoperative outcomes.

COLLABORATORS The following members of the Perihilar Cholangiocarcinoma collaboration group: A. Andreou, F. Bartsch, C. Benzing, S. Buettner, I. Capobianco, P. de Reuver, E. de Savornin Lohman, C. H. C. Dejong, M. Efanov, J. I. Erdmann, L. C. Franken, G. Frascaroli, M. C. Giglio, C. Gomez-Gavara, F. Heid, J. N. M. IJzermans, H. Jansson, M. A. P. Ligthart, S. K. Maithel, M. Malago, H. Z. Malik, P. Muiesan, S. W. M. Olde Damink, E. Pando, L. M. Quinn, F. Ratti, K. J. Roberts, J. Rolinger, A. Ruzzenente, E.
Schadde, M. Serenari, A. Sultana, R. Troisi, S. van Laarhoven, J. L. A. van Vugt.

FUNDING No sources of funding were used to assist in the preparation of this study.

DISCLOSURE Pim B. Olthof, Luca Aldrighetti, Ruslan Alikhanov, Matteo Cescon, Bas Groot Koerkamp, William R. Jarnagin, Silvio Nadalin, Johann Pratschke, Moritz Schmelze, Ernesto Sparrelid, Hauke Lang, Alfredo Guglielmi, and Thomas M. van Gulik have no conflicts of interest to declare.

OPEN ACCESS This article is licensed under a Creative Commons Attribution 4.0 International License, which permits use, sharing, adaptation, distribution and reproduction in any medium or format, as long as you give appropriate credit to the original author(s) and the source, provide a link to the Creative Commons licence, and indicate if changes were made. The images or other third party material in this article are included in the article's Creative Commons licence, unless indicated otherwise in a credit line to the material. If material is not included in the article's Creative Commons licence and your intended use is not permitted by statutory regulation or exceeds the permitted use, you will need to obtain permission directly from the copyright holder. To view a copy of this licence, visit http://creativecommons. org/licenses/by/4.0/.

\section{REFERENCES}

1. Narula N, Aloia TA. Portal vein embolization in extended liver resection. Langenbecks Arch Surg. 2017;402(5):727-35.

2. Glantzounis GK, Tokidis E, Basourakos SP, Ntzani EE, Lianos GD, Pentheroudakis G. The role of portal vein embolization in the surgical management of primary hepatobiliary cancers, A systematic review. Eur J Surg Oncol. 2017;43(1):32-41.

3. Makuuchi M, Thai BL, Takayasu K, et al. Preoperative portal embolization to increase safety of major hepatectomy for hilar bile duct carcinoma: a preliminary report. Surgery. 1990;107(5):521-27.

4. Shindoh J, Tzeng CW, Aloia TA, et al. Safety and efficacy of portal vein embolization before planned major or extended hepatectomy: an institutional experience of 358 patients. $J$ Gastrointest Surg. 2014;18(1):45-51.

5. van Lienden KP, van den Esschert JW, de Graaf W, et al. Portal vein embolization before liver resection: a systematic review. Cardiovasc Intervent Radiol. 2013;36(1):25-34.

6. Farges $\mathrm{O}$, Belghiti J, Kianmanesh R, et al. Portal vein embolization before right hepatectomy: prospective clinical trial. Ann Surg. 2003;237(2):208-17.

7. Yokoyama Y, Nagino M, Nimura Y. Mechanism of impaired hepatic regeneration in cholestatic liver. $J$ Hepatobiliary Pancreat Surg. 2007;14(2):159-66.

8. Dixon JM, Armstrong CP, Duffy SW, Davies GC. Factors affecting morbidity and mortality after surgery for obstructive jaundice: a review of 373 patients. Gut. 1983;24(9):845-52.

9. Kloek JJ, van der Gaag NA, Aziz Y, et al. Endoscopic and percutaneous preoperative biliary drainage in patients with suspected hilar cholangiocarcinoma. J Gastrointest Surg. 2010;14(1):119-25.

10. Farges O, Regimbeau JM, Fuks D, et al. Multicentre European study of preoperative biliary drainage for hilar cholangiocarcinoma. Br J Surg. 2013;100(2):274-83.

11. Ribero D, Zimmitti G, Aloia TA, et al. Preoperative cholangitis and future liver remnant volume determine the risk of liver failure 
in patients undergoing resection for hilar cholangiocarcinoma. $J$ Am Coll Surg. 2016;223(1):87-97.

12. Olthof PB, Wiggers JK, Groot Koerkamp B, et al. Postoperative liver failure risk score: identifying patients with resectable perihilar cholangiocarcinoma who can benefit from portal vein embolization. J Am Coll Surg. 2017;225(3):387-94.

13. Nuzzo G, Giuliante F, Ardito F, et al. Improvement in perioperative and long-term outcome after surgical treatment of hilar cholangiocarcinoma: results of an Italian multicenter analysis of 440 patients. Arch Surg. 2012;147(1):26-34.

14. Higuchi R, Yamamoto M. Indications for portal vein embolization in perihilar cholangiocarcinoma. $J$ Hepatobiliary Pancreat Sci. 2014;21(8):542-49.

15. Yokoyama Y, Nagino M, Nishio H, Ebata T, Igami T, Nimura Y. Recent advances in the treatment of hilar cholangiocarcinoma: portal vein embolization. $J$ Hepatobiliary Pancreat Surg. 2007;14(5):447-54.

16. Palavecino M, Abdalla EK, Madoff DC, Vauthey JN. Portal vein embolization in hilar cholangiocarcinoma. Surg Oncol Clin N Am. 2009;18(2):257-67.

17. van der Gaag NA, Rauws EA, van Eijck $\mathrm{CH}$, et al. Preoperative biliary drainage for cancer of the head of the pancreas. $N$ Engl $J$ Med. 2010;362(2):129-37.

18. Coelen RJS, Roos E, Wiggers JK, et al. Endoscopic versus percutaneous biliary drainage in patients with resectable perihilar cholangiocarcinoma: a multicentre, randomised controlled trial. Lancet Gastroenterol Hepatol. 2018;3(10):681-90.

19. Rahbari NN, Garden OJ, Padbury R, et al. Post-hepatectomy haemorrhage: a definition and grading by the International Study Group of Liver Surgery (ISGLS). HPB (Oxford). 2011;13(8):528-35.

20. Koch M, Garden OJ, Padbury R, et al. Bile leakage after hepatobiliary and pancreatic surgery: a definition and grading of severity by the International Study Group of Liver Surgery. Surgery. 2011;149(5):680-88.

21. Rahbari NN, Garden OJ, Padbury R, et al. Posthepatectomy liver failure: a definition and grading by the International Study Group of Liver Surgery (ISGLS). Surgery. 2011;149(5):713-24.

22. Nagino M, Kamiya J, Nishio H, Ebata T, Arai T, Nimura Y. Two hundred forty consecutive portal vein embolizations before extended hepatectomy for biliary cancer: surgical outcome and long-term follow-up. Ann Surg. 2006;243(3):364-72.

23. Olthof PB, Miyasaka M, Koerkamp BG, et al. A comparison of treatment and outcomes of perihilar cholangiocarcinoma between Eastern and Western centers. HPB (Oxford). 2019;21(3):345-51.

24. Kawamura T, Noji T, Okamura $\mathrm{K}$, et al. Postoperative liver failure criteria for predicting mortality after major hepatectomy with extrahepatic bile duct resection. Dig Surg. 2019;36(2):158-65.

25. Yokoyama Y, Ebata T, Igami T, et al. The Predictive Value of Indocyanine Green Clearance in Future Liver Remnant for
Posthepatectomy Liver Failure Following Hepatectomy with Extrahepatic Bile Duct Resection. World $J$ Surg. 2016;40(6):1440-47.

26. Franken LC, Schreuder AM, Roos E, et al. Morbidity and mortality after major liver resection in patients with perihilar cholangiocarcinoma: a systematic review and meta-analysis. Surgery. 2019;165(5):918-28.

27. Wiggers JK, Groot Koerkamp B, Cieslak KP, et al. Postoperative mortality after liver resection for perihilar cholangiocarcinoma: development of a risk score and importance of biliary drainage of the future liver remnant. J Am Coll Surg. 2016;223(2):321-31.

28. Olthof PB, Coelen RJ, Wiggers JK, Besselink MG, Busch OR, van Gulik TM. External biliary drainage following major liver resection for perihilar cholangiocarcinoma: impact on development of liver failure and biliary leakage. HPB (Oxford). 2016;18(4):348-53.

29. Olthof PB, Coelen RJS, Bennink RJ, et al. (99 m)Tc-mebrofenin hepatobiliary scintigraphy predicts liver failure following major liver resection for perihilar cholangiocarcinoma. HPB (Oxford). 2017;19(10):850-58.

30. Yokoyama Y, Nishio H, Ebata T, Igami T, Sugawara G, Nagino $M$. Value of indocyanine green clearance of the future liver remnant in predicting outcome after resection for biliary cancer. Br J Surg. 2010;97(8):1260-68.

31. Rassam F, Olthof PB, Bennink RJ, van Gulik TM. Current Modalities for the Assessment of Future Remnant Liver Function. Visc Med. 2017;33(6):442-48.

32. Haegele S, Reiter S, Wanek D, et al. Perioperative non-invasive indocyanine green-clearance testing to predict postoperative outcome after liver resection. PLoS ONE. 2016;11(11):e0165481.

33. Ebata T, Yokoyama Y, Igami T, Sugawara G, Takahashi Y, Nagino M. Portal vein embolization before extended hepatectomy for biliary cancer: current technique and review of 494 consecutive embolizations. Dig Surg. 2012;29(1):23-9.

34. Wiggers JK, Groot Koerkamp B, Coelen RJ, et al. Preoperative biliary drainage in perihilar cholangiocarcinoma: identifying patients who require percutaneous drainage after failed endoscopic drainage. Endoscopy. 2015;47(12):1124-31.

35. Rassam F, Roos E, van Lienden KP, et al. Modern work-up and extended resection in perihilar cholangiocarcinoma: the AMC experience. Langenbecks Arch Surg. 2018;403(3):289-307.

36. Nakeeb A, Pitt HA, Sohn TA, et al. Cholangiocarcinoma. A spectrum of intrahepatic, perihilar, and distal tumors. Ann Surg. 1996;224(4):463-73; discussion 473-465.

Publisher's Note Springer Nature remains neutral with regard to jurisdictional claims in published maps and institutional affiliations. 